\title{
VIEWPOINT
}

\section{"Cycling is Not Going to Occur Naturally": A View on the Research Agenda for Bicycle Mobility in Urban South Africa}

\author{
Gail Jennings \\ Centre for Transport Studies, University of Cape Town, ZA \\ gail@gailjennings.co.za
}

While drafting might be an effective bicycle racing practice, closely following someone else's lead is not necessarily the best course of action when it comes to bicycle planning - particularly in emerging or starter cycling cities that have dramatically different complexities, contexts, and urban forms to the exemplars of the literature. This contribution reflects on the knowledge gaps, policy transfer concerns and most pressing research needs in South African cities, if the institutional and activist promotion of everyday cycling is to achieve its objectives. From the outset, a better understanding of the role played by past and current inequity on cycling acceptability is required. A mindful examination of who promotes cycling, to whom, and how, is key: a narrative that seems shaming, coercive or a knowing better is an unwise basis from which to redirect our automobile trajectory.

Keywords: policy transfer; active mobility; starter cycling cities; non-motorised transport; South Africa

"We want to see more people cycling so we have to get out there and make it happen. It's not going to occur naturally."

Former Executive Mayor, Parks Tau, City of Johannesburg, May 2016 (Mead, 2016)

\section{Introduction}

Bicycle travel is virtually absent in South Africa's flagship 'cycling city', Cape Town, with approximately $0.7 \%$ of modeshare (Hitge and Joubert, 2021). In Johannesburg, it is much the same (Morgan, 2019a). When it comes to other modes, the walking: public transport (including rail): private car mode, split for Cape Town was 9\%:38\%:53\% in 2018 (Jobanputra et al., 2021).

In Cape Town, the municipal authority has recently developed a strong policy commitment in the form of a Cycling Strategy (City of Cape Town, 2017) ${ }^{1}$ to increase the share of cycling to $8 \%$ by 2030 . However, there is little evidence to suggest any meaningful progress or shift to date, and there is no clear approach to doing so (Hitge and Joubert, 2021).

This article proposes that along almost the entire bicycle journey chain, from precontemplation to routine behaviour (Prochaska and DiClemente, 1983; Prochaska, DiClemente and Norcross, 1992), approaches to cycling interventions in South African cities are thwarted by a shallowness of attention and evidence. It may be, as is Nello-Deakin's (2020) view from the global north, that further cycling research is largely redundant and that growing cycling is a simple formula of providing more road space for cyclists at the cost of motorised traffic. But Castañeda's (2021) global south perspective has more resonance: that in cities such as Cape Town and Johannesburg, with complex political challenges and highly conflicting narratives around cycling and equity (Jennings, 2016), the desires and aspirations of inhabitants warrant further enquiry, and there is much still to be known.

Although a pre-apartheid cycling culture did exist within a less-motorised South Africa (Morgan, 2019b), cycling's policy, research, and advocacy impetus post-apartheid did not emerge primarily from intended beneficiaries but initially from an international consultancy and scholarly agenda and a global 'best practice' (Department of Environmental Affairs (DEA), 2014; South African National Department of Transport (NDoT), 2014). Later priorities emerged in alignment with global climate imperatives (Jennings, 2018, 2021; Morgan, 2019a, 2020). As we know, the experiences of European (and indeed, any) cycling cities are not universal (Castañeda, 2021); if nothing else, COVID-19 mobility 
responses have shown us this. ${ }^{2}$ There are no easy 'best-practices' to transfer from cities that share the inequity and political and spatial characteristics of urban South Africa and that also have the high rates of cycling to which Cape Town in particular aspires.

Transportation research in South Africa ${ }^{3}$ has until recently been situated almost entirely within the civil engineering and urban planning domains (Porter, Abane and Lucas, 2020). Bicycle transport more specifically is a fairly new practitioner and research domain, gaining in prominence since the 2008 inception of the University of Cape Town's African Centre for Excellence for Studies in Public and Non-Motorised Transport. In South Africa the term Non-Motorised Transport (NMT) continues to be used in policy and advocacy to refer to walking, cycling, skateboarding and other such modes; terms such as active mobility or active transport are seldom used, in part because a goal of walking and cycling planning is to reduce the long distances and high levels of 'activity' that characterise many of these journeys, and partly to clearly distinguish bicycle mobility from sport/leisure and its elitist framing (see, e.g., Dawjee, 2021). Research since 2008 has been concerned mostly with quantitative measures, demand estimation, and infrastructure or safety standards (Behrens et al., 2016). Public health practitioners are highly visible in the cycling research fields in west and east Africa, ${ }^{5}$ but less so in South Africa. Little is known of the impact of the bicycle mobility interventions intended to deliver on congestion or carbon mitigation, accessibility or poverty alleviation. Even less research has been directed towards the lived experiences of cyclists, their needs and practices in using a bicycle to access social networks, healthcare, livelihoods or other services beyond conventional work-trip planning. New work in Johannesburg by anthropologist/historian Morgan (2020) is a welcome departure, and social media is always a source of valuable insight.

As Morgan's work in Johannesburg highlights (Morgan, 2019a), bicycle lanes - the set piece of bicycle planning in South Africa - do not guarantee an increase in cycling or a new cycling culture. When these bike lanes represent an end-state ideal without the development processes that other cycling cities had in place first (Hitge and Van Dijk, 2012), cycling behaviour change is even less likely.

So while the greatest gaps in the knowledge are in the social and behavioural sciences, it is also here that we are likely to find the keys to unlock bicycle potential in South Africa.

\section{Knowledge Gaps, Policy, Research}

The international literature concurs that bicycle travel has climate, congestion, and poverty mitigation potential, as well as positive individual and public health, and urban quality impacts. These outcomes are stated objectives in local bicycle policies too. In addition, South Africa engages an explicit redressive discourse - seeking to use cycling to counter past imbalances (Provincial Government Western Cape (PGWC), 2009), bridge economic gaps, support local community facilities, facilitate economic development and equitable access, and ease the burden of poverty (NDoT, 2008). Yet there is a dearth of research that examines and quantifies these claims and potentials in our local urban contexts. In South Africa, bicycle lanes and their installation have become contested interventions, seen as misdirected public resources amid unmet public transport, water, sanitation and housing needs (Du Preez, 2011; Future Cape Town, 2011; Mtyala, 2013; Pollitt, 2014; Jennings, 2016; Jennings et al., 2021). Cycling can only effectively facilitate such redress if the intended beneficiaries are able to and wish to (have a 'propensity to') use bicycle transport rather than better-quality and more affordable public transport, and where land-use patterns facilitate accessibility across acceptable cycling distances. In this sense, many assumptions underpinning arguments for bicycles as necessarily pro-poor or socially just are insufficiently examined (Martens et al., 2016), and the extent to which bicycle travel in our city contexts can redress spatial inequity and deliver transport justice is unclear.

Unexamined assumptions in planning and promotion are likely contributors to South Africa's persistently low cycling rates, despite decades of policy, intermittent infrastructure build, and occasional optimism:

'Aah, there was once so much momentum. 2011, 2012, 2013, that was Cape Town's heyday ... For a while [after the transport infrastructure boost of the 2010 FIFA World Cup], it seemed that bicycle mobility momentum was unstoppable'. ${ }^{6}$

It is difficult for cities to justify directing resources to bicycle infrastructure that appears to go unused. Testing of routes and interventions, through pilots and flexible, temporary infrastructure (tactical urbanism approaches), may be able to provide evidence of impact and success, and bolster user, political, and budgetary support (Jennings et al., 2021). But even so, bicycle route planning needs attention before infrastructure: network design in South Africa involves a curious mix of imported models of latent demand with a neglect of actual usage (Vorster and Zuidgeest, 2019). Research prepared in Cape Town in 2020 (Hitge and Joubert, 2021) is of the view that cycling cities do not sufficiently acknowledge the 'nature, quantum or location of potential demand for cycling'.

\footnotetext{
${ }^{2}$ In one example, where pop-up bicycle facilities became increasingly visible during the 2020 pandemic in cycling exemplar European cities and a number of US and Latin American cities, these were almost entirely absent in Sub-Saharan Africa (Abubaker, Tuniz and Oursler, 2020).

3 And Sub-Saharan African cities more generally.

${ }^{4}$ And in Africa more generally.

${ }^{5}$ Interviews conducted by the author in December 2020.

6 The interview excerpts shared here were conducted during 2019 as a part of wider doctoral research that explores the connections and relationships between policy and personal discourses, and the ways in which private car owners understand their reasons for cycling for transport.
} 
But given the absence of revealed data to describe distinguishing characteristics of everyday cyclists in Cape Town, and thereby a difficulty in estimating demand, Hitge and Joubert (2021) propose using behavioural theories that could predict who is more likely to cycle than others. A good approach, but the knowledge about local cycling behaviour is also virtually non-existent. In one example, although road and personal safety is a significant concern, commuter cyclists in Cape Town have shown a preference for direct routes along arterial roads with mixed traffic rather than the indirect and more remote routes where bicycle facilities have at times been installed. Further, commuter or everyday cyclists are relatively comfortable travelling distances significantly longer than the 5 to $10 \mathrm{~km}$ 'best-practice' standards (Petzer, 2016; Jennings et al., 2021). Yet a broad range of cyclists themselves are seldom adequately sought and included in the identification of optimal routes, and methods for route selection are insufficiently open and transparent (Vorster and Zuidgeest, 2019). This leaves users dissatisfied and costly bicycle lanes unused in favour of travelling with mixed road traffic instead.

Cape Town's transport authority interprets behaviour change narrowly as trying to get people to ride once infrastructure had been developed, rather than understanding user needs and behaviours as formative research ahead of hard infrastructure build. After the fact, 'market[ing of] ... completed routes ... within $1 \mathrm{~km}$ of the route' and 'advertising events on the City's website' is Cape Town's official approach (CCT, 2018). Building infrastructure, then having to 'market' it to a not necessarily interested audience, is costly and time-consuming (Hitge and Joubert, 2021).

For these above reasons alone, the circumstances under which potential cyclists might choose this mode, and the routes they prefer, the distances they might decide to travel and the diversity of motivations for riding, require greater insight if effective interventions are to be developed. It cannot be assumed that practices and preferences in compact cities with integrated public transport constitute good planning elsewhere.

Most people who cycle as a transport mode in South African cities are men with low incomes, who live in low-income areas and who cycle out of economic necessity (Jennings, 2016; Jennings, Petzer and Goldman, 2017; Irlam, 2018; Morgan, 2020). The majority of scholarly work investigates this population. There is therefore some understanding of the barriers to cycling (access to affordable bicycles) and the stated motivations for cycling among this particular cohort (Irlam, 2016) - that is, to save on public transport costs, or for fitness and mental health (Bechstein, 2010; Boulle, 2013).

There is little known other than my own recent work (Jennings, 2021) and that of Morgan (2020) as to why private vehicle owners might choose cycling as a mode of travel in Cape Town and Johannesburg. As contributors to the congestion and emissions that authorities wish to mitigate through cycling, car users constitute a primary marketing target, yet are almost entirely un-investigated. In the absence of this interrogation, motivations are assumed to be those of an international cohort: environmental awareness, congestion avoidance, and climate consciousness.

Marketing, in as much as it takes place, is built on these above assumptions, and messaging is deployed in a broad sweep. In one example, encouragement to intended cyclists in a low-income area in Johannesburg - where public transport and walking are the primary modes - centred on bicycles as 'alternatives to private cars', an opportunity to 'reduce greenhouse gas emissions', 'promote renewable energy sources' and facilitate 'broad climate change awareness' (Magangane, 2014). Attempts to 'brand' bicycle travel as aspirational may serve the already conflictive narrative, where 'green' rather than utility entrenches the symbology of cycling as an 'additional option [for] the [already] overprivileged' and a gimmick for the wealthy (Ndenze, 2011).

More so within car-dominated and low-cycling cities, the roles of identities, meanings, and lifestyles, in addition to focusing on infrastructure, are what might shift cycling behaviours (Aldred, 2012; Aldred and Jungnickel, 2014). And although some studies (Mahapa, 2003; Boulle, 2013; Mashiri et al., 2013; Irlam and Zuidgeest, 2018), and a fair bit of anecdote from practitioners, suggest that there may be social norms around the acceptability of bicycling as a transport mode (or sport) among women in South Africa, there has been no systematic research to support (or detract from) this hypothesis. Likewise, it is often stated by practitioners and decision- or policy makers that cycling as transport has low status, is stigmatised, and regarded by potential users as a highly visible marker of poverty. Yet one of the few studies in urban South Africa to directly ask users themselves about status found the opposite: when interviewing cyclists in low-income areas in Tshwane, Bechstein (2010) learned that cycling was not only a cheap mode, but also seen as good exercise and 'a cool' means of travelling.

In the same vein, cyclists with low incomes are assumed to be 'captive' to the mode, which Bechstein defines as those who would stop cycling if they could afford public transport (Bechstein, 2010, p33). Yet contrary to assumption, her interviewees expressed 'strong affinity' towards cycling, and 'feel comfortable racing the traffic and also appreciate the psychological well-being they received after they had cycled' (Bechstein, 2010, p35).

\section{Looking Ahead}

There is much work that needs to be done on interrogating these tropes around meaning, motivation and mode. Spurred on by the hope for reduced congestion, reduced poverty, improved public health and an opportunity to meet international climate commitments, cities in South Africa wish to promote cycling as a mode to people who currently drive as well as those who walk or take public transport. Yet critical questions are not being asked - not least of which are those around 'responsibilisation' (Aldred, 2012) and who benefits from the cycling agenda. From conceptualisation of the 'problems' that cycling may mitigate, to understanding the diversity of the 'target audience' and designing user-centric messages and networks, planning approaches lead from limited local evidence and knowledge, and largely 
follow the broad assumptions of elsewhere. Although these is a growing body of work around cycling in South Africa, social research in this area is undervalued to date.

Castañeda (2021) proposes that we critically evaluate the effects of cycling best practices, and create new standards and frames of reference. This article has tried to outline some of these standards and frames of reference that would benefit from re-evaluation.

South African cities' spatial inequities, sprawl, and automobile hegemony already render cycling a tricky mode to encourage - but more than this, the touted 'solution' of bicycle transport sits uneasily within a discourse of negative symbolic meanings (Morgan, 2019a). To reference a passage I have used before, everyday cycling in South African cities exists within a spatial context where mobility was historically deployed as a mechanism of social control (Czeglédy, 2004). From the outset, a better understanding of the role played by past and current inequity on cycling acceptability (Morgan, 2020) is required. A mindful examination of who promotes cycling, to whom, and how is key: a narrative that seems shaming, coercive, or a knowing better, is an unwise basis from which to redirect our automobile trajectory (Jennings, 2018).

\section{Funding Information}

This contribution is drawn partially from doctoral research (Department of Civil Engineering, Centre for Transport Studies, University of Cape Town), and partially from research funded by UKAID through the UK Foreign, Commonwealth \& Development Office under the High-Volume Transport Applied Research COVID-19 Response and Recovery Programme, managed by IMC Worldwide.

\section{Competing Interests}

The author has no competing interests to declare.

\section{References}

Abubaker, I, Tuniz, J and Oursler, A. 2020. As the coronavirus looms, can African cities become more walkable and bikeable?. TheCityFix, 12 August. Available from https://thecityfix.com/blog/coronavirus-looms-can-african-citiesbecome-walkable-bikeable-iman-abubaker-janene-tuniz-anna-oursler/ [Accessed: 23 October 2020].

Aldred, R. 2012. The role of advocacy and activism in shaping cycling policy and politic. In Parkin, J (ed.), Cycling and sustainability, 83-110. Bingley: Emerald. DOI: https://doi.org/10.1108/S2044-9941(2012)0000001006

Aldred, R and Jungnickel, K. 2014. Why culture matters for transport policy: the case of cycling in the UK. Journal of Transport Geography, 34: 78-87. DOI: https://doi.org/10.1016/j.jtrangeo.2013.11.004

Bechstein, E. 2010. Cycling as a supplementary mode to public transport: a case study of low-income commuters in South Africa. 29th Southern African transport conference, 16-19 August. Pretoria: Transportation Research Board of the National Academies (NRB).

Behrens, R, et al. 2016. Mobility and access in Sub-Saharan African cities: the state of knowledge and research environments. VREF, Mobility and Access in African Cities.

Boulle, MJ. 2013. The role of bicycles and bicycle empowerment centres in improving the mobility and livelihoods of the poor, and assisting with low-carbon development in Cape Town. Masters thesis. University of Cape Town, 102.

Castañeda, P. 2021. Cycling case closed? A situated response to Samuel Nello-Deakin's "Environmental determinants of cycling: Not seeing the forest for the trees?". Journal of Transport Geography, 90: 2020-2022. DOI: https://doi. org/10.1016/j.jtrangeo.2020.102947

CCT. 2018. Comprehensive Integrated Transport Plan 2018-2023, City of Cape Town. Transport Plan. City of Cape Town.

City of Cape Town. 2017. Cycling Strategy for the City of Cape Town: Policy Number 55219. https://resource.capetown. gov.za/documentcentre/Documents/Bylaws\%20and\%20policies/Cycling\%20Strategy.pdf.

Czegledy, AP. 2004. Getting around Town: Transportation and the Built Environment in Post-Apartheid South Africa. City and Society, 16: 63-92. DOI: https://doi.org/10.1525/city.2004.16.2.63

Dawjee, HM. 2021. Cyclists, cyclists everywhere and not a care to spare. Eyewitness News. Available from Https:// Ewn.Co.Za/2021/01/08/Haji-Mohamed-Dawjee-Cyclists-Cyclists-Everywhere-And-Not-A-Care-To-Spare [Accessed: 22 June 2021].

DEA. 2014. NMT best practice manual. Department of Environmental Affairs, South Africa; German Cooperation; KFW.

Du Preez, M. 2011. The Powerful Poor. News24, 11 May. Available from https://www.news24.com/news24/Columnists/MaxduPreez/The-powerful-poor-20110511 [Accessed 22 June 2021].

Future Cape Town. 2011. The "racist" cycle lanes Tony Ehrenreich failed to see. Our Future Cities, 24 April. Available from http://ourfuturecities.co/2011/04/the-racist-cycle-lanes-tony-ehrenreich-failed-to/ [Accessed 22 June 2021].

Hitge, G and Joubert, J. 2021. A nodal approach for estimating potential cycling demand. Journal of Transport Geography, 90: 102943. DOI: https://doi.org/10.1016/j.jtrangeo.2020.102943

Hitge, G and Van Dijk, ENR. 2012. Incremental approach to public transport system improvements. Document Transformation Technologies. Available from https://repository.up.ac.za/handle/2263/20420 [Accessed 16 February 2021].

Irlam, J. 2016. Barriers to cycling mobility in Masiphumelele. Masters thesis. University of Cape Town.

Irlam, JH and Zuidgeest, M. 2018. Barriers to cycling mobility in a low-income community in Cape Town: A Best-Worst Scaling approach. Case Studies on Transport Policy, 6(4): 815-823. DOI: https://doi.org/10.1016/j.cstp.2018.10.003 
Jennings, G. 2016. Freedom of movement: an enquiry into utility cycling and social justice in post-apartheid Cape Town, 1994-2015. In: Golub, A, et al. (eds.), Bicycle justice and urban transformation, 235-256. Abingdon: Routledge.

Jennings, G. 2018. Building a socially just bicycle programme in an unequal city: the case of Johannesburg. Gauteng CityRegion Observatory.

Jennings, G. 2021. Cycling for change: exploring the role of carbon-consciousness among Cape Town's intentional cyclists. In Zuev, D, Psarikidou, K and Popan, C. (eds.), Cycling societies: innovations, inequalities and governance, 219-238. Abingdon: Routledge. DOI: https://doi.org/10.4324/9780429321092-17

Jennings, G, et al. 2021. Learning from Covid-19 pop-up bicycle infrastructure: an investigation into flexible and userled bicycle planning in Cape Town, Nairobi, and Kampala. Funded by UKAID through the UK Foreign, Commonwealth \& Development Office under the High Volume Transport Applied Research Programme, managed by IMC Worldwide.

Jennings, G, Petzer, B and Goldman, E. 2017. When bicycle lanes are not enough: growing mode share in Cape Town, South Africa: an analysis of policy and practice. In: Non-motorized transport integration into urban transport planning in Africa. Routledge. DOI: https://doi.org/10.4324/9781315598451-13

Jobanputra, R, et al. 2021. Fast-tracking public transport priority: investigating the potential of Tactical Transit Lanes in mitigating the impact of COVID-19 in cities in Sub-Saharan Africa. This research was funded by UKAID through the UK Foreign, Commonwealth \& Development Office under the High Volume Transport Applied Research Programme.

Magangane, N. 2014. Cycle paths launched in Orlando. Soweto Urban, 24 October. Available from https://sowetourban.co.za/14994/cycle-paths-launched-orlando/ [Accessed: 15 March 2021].

Mahapa, S. 2003. Integrating gender into World Bank Financed Transport Programmes: case study. South Africa: Shova Kalula. The World Bank. Available from https://documents.worldbank.org/en/publication/documents-reports/documentdetail/294371468334767643/integrating-gender-into-world-bank-financed-transport-programmes-casestudy-south-africa-shova-kalula.

Martens, K, et al. 2016. Advancing discussions of cycling interventions based on social justice. In: Bicycle justice and urban transformation: biking for all? Abingdon: Routledge. DOI: https://doi.org/10.4324/9781315668840-6

Mashiri, M, et al. 2013. Building a sustainable platform for low-cost mobility in South Africa. In: Southern African Transport Conference 2013, 8-13 July. Pretoria, University of Pretoria, 198-212. Available from https://repository.up.ac. za/handle/2263/32278?show=full

Mead, N. 2016. Can Johannesburg reinvent itself as Africa's first cycle-friendly megacity?. The Guardian, 24 May. Available from http://www.theguardian.com/cities/2016/may/24/johannesburg-africa-first-cycle-friendly-megacitybicycles [Accessed 15 March 2021].

Morgan, N. 2019a. Cycling infrastructure and the development of a bicycle commuting socio-technical system: the case of Johannesburg. Applied Mobilities, 4(1): 106-123. DOI: https://doi.org/10.1080/23800127.2017.1416829

Morgan, N. 2019b. How apartheid killed Johannesburg's cycling culture. The Guardian, 26 June. Available from http:// www.theguardian.com/cities/2019/jun/26/how-apartheid-killed-johannesburgs-cycling-culture- [Accessed 10 March 2021].

Morgan, N. 2020. The stickiness of cycling: residential relocation and changes in utility cycling in Johannesburg. Journal of Transport Geography, 85: 102734. DOI: https://doi.org/10.1016/j.jtrangeo.2020.102734

Mtyala, Q. 2013. Cycling lanes turned into "smoking pits". timesLIVE, 8 October. Available from https://www.timeslive. co.za/news/south-africa/2013-10-08-cycling-lanes-turned-into-smoking-pits/ [Accessed 22 June 2021].

Ndenze, B. 2011. Cosatu blasts DA for bicycle lanes. Available from https://www.iol.co.za/news/south-africa/westerncape/cosatu-blasts-da-for-bicycle-lanes-1055579 [Accessed 22 June 2021].

NDoT. 2008. Non-motorised transport policy - draft: National Department of Transport, South Africa. National policy. National Department of Transport.

NDoT. 2014. NMT facility guidelines: policy and legislation, panning, design and operations. South Africa: South African National Department of Transport.

Nello-Deakin, S. 2020. Environmental determinants of cycling: not seeing the forest for the trees?. Journal of Transport Geography, 85: 102704. DOI: https://doi.org/10.1016/j.jtrangeo.2020.102704

Petzer, B. 2016. A contextual analysis of cycling environment assessment tools in a Cape Town Mobility Corridor. Masters thesis. University of Cape Town.

PGWC. 2009. NMT in the Western Cape - draft strategy. Provincial Government Western Cape. Available from: https:// www.westerncape.gov.za/files/documents/2009/5/pgwc_nmt_report_english_march_09_upload_3.pdf.

Pollitt, R. 2014. Our mirror: bicycles, water, power, Zuma?. Daily Maverick, 6 October. Available from https://www. dailymaverick.co.za/opinionista/2014-10-06-our-mirror-bicycles-water-power-zuma [Accessed: 16 February 2021].

Porter, G, Abane, A and Lucas, K. 2020. User diversity and mobility practices in Sub-Saharan African cities: understanding the needs of vulnerable populations. Volvo Research and Educational Foundations. Gothenberg, Sweden.

Prochaska, JO and DiClemente, CC. 1983. Stages and processes of self-change of smoking: toward an integrative model of change. Journal of Consulting and Clinical Psychology, 51(3): 390-395. DOI: https://doi.org/10.1037/0022006X.51.3.390

Prochaska, JO, DiClemente, CC and Norcross, JC. 1992. In search of how people change: Applications to addictive behaviors. American Psychologist, 47(9): 1102-1114. DOI: https://doi.org/10.1037/0003-066X.47.9.1102 
Vorster, J and Zuidgeest, M. 2019. Cycle route network development and evaluation using spatial multi-criteria analysis and shortest path analysis. 38th International Southern African Transport Conference on "Disruptive transport technologies - is South and Southern Africa ready?" Pretoria, 8-11 July, 16. Available from: http://hdl.handle. net/2263/74292.

How to cite this article: Jennings, G. 2021. "Cycling is Not Going to Occur Naturally": A View on the Research Agenda for Bicycle Mobility in Urban South Africa. Active Travel Studies: An Interdisciplinary Journal, 1(1): 7, 1-6. DOl: https://doi.org/10.16997/ ats.1109

Copyright: ( $) 2021$ The Author(s). This is an open-access article distributed under the terms of the Creative Commons Attribution 4.0 International License (CC-BY 4.0), which permits unrestricted use, distribution, and reproduction in any medium, provided the original author and source are credited. See http://creativecommons.org/licenses/by/4.0/. 